\title{
UNIFORM ASYMPTOTICS FOR THE TAIL OF THE DISCOUNTED AGGREGATE CLAIMS WITH UTAI CLAIM SIZES
}

\author{
YONGFANG CUI AND KAIYONG WANG*
}

Abstract. This paper considers a risk model, where the price process of the investment portfolio is described by a geometric Lévy process. When the claim sizes are UTAI, the paper obtains the uniform asymptotics of the tail probability of the discounted aggregate claims and the finite-time ruin probability for the claim sizes with dominated varying distributions. The obtained results extend some existed results.

Mathematics subject classification (2020): 62P05, 62E10, 60F05.

Keywords and phrases: Discounted aggregate claims, upper tail asymptotic independent claims, dominatedly varying tail, Lévy process.

\section{REFERENCES}

[1] N. H. Bingham, C. M. Goldie, J. L. Teugels, Regular Variation, Cambridge University Press, Cambridge, 1987.

[2] Y. CHEN, K. W. NG, The ruin probability of the renewal model with constant interest force and negatively dependent heavy-tailed claims, Insurance: Mathematics and Economics, 2007, 40 (3): $415-$ 423.

[3] R. Cont, P. Tankov, Financial Modelling with Jump Processes, Chapman \& Hall/CRC, Boca Raton, 2004.

[4] P. Embrechts, C. Klüppelberg, T. Mikosch, Modelling Extremal Events for Insurance and Finance, Springer, Berlin, 1997.

[5] C. M. Goldie, Subexponential distributions and diminated-vatiation tails, Journal of Applied Probability, 1978, 15 (2): 440-442.

[6] X. HAO, Q. TANG, A uniform asymptotic estimate for discounted aggregate claims with subexponential tails, Insurance Mathematics \& Economics, 2008, 43 (1): 116-120.

[7] P. Jostein, H. K. GJESSING, Ruin theory with stochastic return on investments, Advances in Applied Probability, 1997, 29 (4): 965-985.

[8] V. Kalashnikov, R. Norberg, Power tailed ruin probabilities in presence of risky investment, Stochastic Processes and Their Applications, 2002, 98 (2): 211-228.

[9] J. LI, Asymptotics in a time-dependent renewal risk model with stochastic return, Journal of Mathematical Analysis and Applications, 2012, 387 (2): 1009-1023.

[10] K. MAulik, S. Resnick, Characterizations and examples of hidden regular variation, Extremes, 2004, 7 (1): 31-67.

[11] J. PENG, D. WANG, Asymptotics for ruin probabilities of a non-standard renewal risk model with dependence structures and exponential Lévy process investment returns, Journal of Industrial and Management Optimization, 2017, 13: 155-185.

[12] J. Peng, D. WAng, Uniform asymptotics for ruin probabilities in a dependent renewal risk model with stochastic return on investments, Stochastics: An International Journal of Probability and Stochastic Processes, 2018, 90: 432-471.

[13] X. SHEN, Z. LIN, The ruin probability of the renewal model with constant interest force and uppertailed independent heavy-tailed claims, Acta Mathematica Sinica, 2010, 26 (9): 1815-1826.

[14] Q. TANG, Heavy tails of discounted aggregate claims in the continuous-time renewal model, Journal of Applied Probability, 2007, 44 (2): 285-294. 
[15] Q. TANG, G. WANG, K. C. YUEn, Uniform tail asymptotics for the stochastic present value of aggregate claims in the renewal risk model, Insurance: Mathematics and Economics, 2010, 46 (2): 362-370.

[16] Q. TANG, G. Tsitsiashvili, Precise estimates for the ruin probability in finite horizon in a discretetime model with heavy-tailed insurance and financial risks, Stochastic Processes and Their Applications, 2003, 108 (2): 299-325.

[17] K. WANG, Y. WANG, Q. GAO, Uniform asymptotics for the finite-time ruin probability of a dependent risk model with a constant interest rate, Methodology and Computing in Applied Probability, 2013, 15 (1): 109-124.

[18] K. WANG, Y. CUI, Y. MAO, Estimates for the finite-time ruin probability of a time-dependent risk model with a Brownian perturbation, Mathematical Problems in Engineering, 2020, Article ID 7130243, 1-5.

[19] Y. YANG, K. WANG, D. G. KonstantinidES, Uniform asymptotics for discounted aggregate claims in dependent risk models, Journal of Applied Probability, 2014, 51 (3): 669-684.

[20] Y. YANG, Y. WANG, Asymptotics for ruin probability of some negatively dependent risk models with a constant interest rate and dominatedly-varying-tailed claims, Statistics and Probability Letters, 2010, 80 (3-4): 143-154.

[21] Y. YANG, K. WANG, J. LiU, Z. ZHANG, Asymptotics for a bidimensional risk model with two geometric Levy price processes, Journal of Industrial and Management Optimization, 2019, 15 (2): 481-505.

[22] L. YI, Y. CHEN, C. SU, Approximation of the tail probability of randomly weighted sums of dependent random variables with dominated variation, Journal of Mathematical Analysis and Applications, 2011, 376 (1): $365-372$. 